\title{
A study on competitiveness of sea and island tourism in Vietnam
}

\author{
Thi Kim Oanh Thai ${ }^{a}$, Manh Dung Tran ${ }^{b^{*}}$, Thi Hong Viet Bui ${ }^{b}$, Thi Thu Ha Doan ${ }^{\mathrm{b}}$ and Quang \\ Thang Dao ${ }^{a}$
}

${ }^{a}$ Vinh University, Vietnam

${ }^{b}$ National Economics University, Vietnam

\section{H R O N I C L E \\ A B S T R A C T}

Article history:

Received: September 52019

Received in revised format: Sep-

tember 52019

Accepted: October 15, 2019

Available online:

October 15,2019

Keywords:

Competitiveness

Destination

Sea and island tourism

Nghe An

\section{Introduction}

Tourism has been identified as a key economic sector in Vietnam (Dong, 2017). Nghe An province just like many other localities throughout the country aims to develop tourism into a key economic sector. This policy has been persevered by all levels of local authority for many years. The travel industry, the same as other businesses, is now facing enormous competitive pressures. Spontaneous tourism, mainly based on available resources, is special, but cannot ensure that destinations have a firm foothold in the travel market, especially in the globalization context. Hence, in order to successfully develop tourism, destinations need to establish their strengths on the basis of building sustainable competitive advantages along with continuous thinking and positioning new competitive advantages, and overcoming the inherent disadvantages. Therefore, it is important to accurately assess competitiveness of these destinations.

Nghe An is a province with great potential for tourism, including sea and island tourism, but the practice shows that the development of sea and island tourism in Nghe An is not proportional to the existing capacity. Nghe An's sea and island tourism is still mainly based on directly exploiting the available natural resources. The added value generated from tourism management is insignificant. The hallmark of Nghe sea and island tourism is not much different from that of the neighboring localities and has not been able to obtain a national and international brand compared with many other localities of Vietnam. Nghe An needs to accurately determine advantages as well as disadvantages in the development of sea and island tourism in order to have effective solutions enhancing the ability to attract visitors to sea and island tourism in Nghe An. In regards this, we conducted a research to evaluate the competitiveness of the sea and island destinations in both theoretical and practical aspects. The selection and application of Dwyer and Kim's model (2003) to assess the competitiveness of the sea and island tourism in Nghe An potentially show a different approach compared with the previous studies.

\footnotetext{
* Corresponding author.

E-mail address: manhdung@ktpt.edu.vn (M. D. Tran) 


\section{Literature review and model}

\subsection{Competitive capability of destinations}

Crouch and Ritchie (1999) define competitiveness of a destination as the ability to create added value leading to increase income and wealth through asset management, processes, attraction and neighboring places as well as through integrating these relationships into a socio-economic model which allows for exploitation while preserving the natural capital of the destination for future generation. This definition is very close to the view of the World Economic Forum, which identifies competitiveness based on the economic benefits that residents of the destination have. This approach is also relevant at the international level by allowing comparisons between countries on the economic benefits of tourism (Dwyer \& Kim, 2003).

Moreover, there are also many other definitions used in practice. The competitiveness of a destination is the ability of the destination to maintain market power and market share and increase them over time. Hassan (2000) argues that the competitiveness of a destination is the ability of the destination to create and integrate value-added products, preserve resources while still retain the market appeal against the competition.

In this study, competitiveness will be understood by Crouch and Ritchie (1999) definition as it has full of common meanings and many similarities with other definitions.

\subsection{Competitiveness assessment model of destinations}

In research as well as in practice, competitiveness assessment of destinations is associated with the areas attracting great academic interest as well as policy makers. There are a number of theoretical models in competitiveness assessment of the destinations which have been proposed, developed and applied. According to Hassan (2000), traditional competitiveness assessment models tend to focus on the supply side or only investigate factors related to the competition between enterprises in the same industry or market. Although the traditional models still can evaluate the current competitiveness, they do not analyse future trends as well as the effects of demand. These traditional models often ignore the unique characteristics of tourism business, equating tourism business with other types of goods and services. Therefore, relying on the traditional models might lead to the inadequacy when making plans for tourism development (Duman \& Kozak, 2010). In order to solve the above problem, scholars have attempted to add a wide range of factors from both supply and demand into the model, and to analyse both the interactions between factors and the operating environment of those factors. The first acknowledged study had a full and comprehensive integration of the factors required for tourism competitiveness from both the supply and the demand sides, was conducted by Crouch and Ritchie (1999). This research, which was developed based on Ritchie and Crouch's (1993) study, and expanded in later studies such as Richie and Crouch (2000, 2003), which are often seen as the theoretical model of competitiveness of destinations. According to Cracolici et al. (2008), Crouch \& Ritchie's studies on tourism competitiveness were originally inspired by Porter (1990). Based on the work of Porter (1990), Ritchie and Crouch (1993, 2000, 2003) and Crouch and Ritchie (1999) developed a competing model for a specific destination. In their studies, tourism competitiveness was built on the basis of a combination of many factors. Accurately calculating the value of each factor as well as the interaction between them will help to identify exactly the strengths that each destination, province or country should rely on to sustainably develop tourism with the highest efficiency. Competitiveness will determine the failure or success of tourism development. Although Crouch and Ritchie (1999) created a quite comprehensive and modern model with required factors for competitiveness, their model was criticized for lack of linkage and interactions between factors (Tanja et al., 2011). In other words, the factors in their model are only considered at static state, the relationship between these factors is usually onesided and quite straightforward. In addition, many scholars argue that their model inclines to the supply factors than the demand factors (Gomezelj \& Mihalič, 2008). Hence, deepening the connection between factors of competitiveness is the direction of development chosen by later scholars. In particular, based on the results of Crouch and Ritchie (1999), Dwyer and Kim (2003) successfully developed a multi-factor model to assess tourism competitiveness and solved the inadequate interaction between factors in the original model (Tanja et al., 2011). In this model, they gathered and diversified important factors of the nation, enterprises and destination competitiveness. Tanja et al. (2011) argued that the model of Dwyer and Kim (2003) retained most of the structure of the model proposed by Crouch and Ritchie (1999). However, Dwyer \& Kim (2003) explained more clearly the interaction between factors that determine tourism competitiveness. They have detailed four components of competitiveness in Crouch and Ritchie (1999) through a series of criteria. For example, while resources in the Crouch and Ritchie (1999) model belonged to a group, these resources, in Dwyer and Kim (2003) model were clearly separated into natural, cultural, and historical resources. The model also emphasizes the importance of demand factors. Thereby, tourists' knowledge and understanding about a destination is the key factor determining the number of tourists. Therefore, the criteria system to quantify the competitiveness index has more diverse components and, at the same time, allow comparisons between countries and between sectors in the tourism industry. However, Dwyer and Kim (2003) indicated that the criteria system in the multi-factor model should be flexibly adjusted when applied. In summary, theoretical model of Dwyer and Kim (2003) presents the following main groups of factors when assessing tourism competitiveness: (i) resources; (ii) situational conditions; (iii) demand; (iv) management; (v) relationship between factors.

\subsection{Competitiveness assessment model for sea and island tourism in Nghe An}

This study is based on Dwyer and Kim's (2003) integrated model of competitiveness assessment for the destination and inherited many advantages of Crouch and Ritchie (1999) and Ritchie and Crouch (2000, 2003). According to Hudson et al. 
(2004), the theoretical basis developed by Crouch and Ritchie is quite comprehensive, complete, widely applicable, and reliable. Besides, Dwyer and Kim (2003) clarified the system of factors as well as the interactions between these factors and emphasized the role of market demand factor. Furthermore, the model of Dwyer and Kim (2003) has also been used successfully in some recent studies, such as Hudson et al. (2004), Enright \& Newton (2005), Cracolici et al. (2008), Crouch (2010). Among these studies, models of competitiveness assessment of coastal areas, as in Enright and Newton's (2005) research and Cracolici et al. (2008) research are paid more attention. These models can be seen as references for creating an appropriate model for Nghe An. In order to have a comprehensive picture of the competitiveness of the sea and island tourism in Nghe An, this study will use all the criteria in Dwyer and Kim (2003) model. However, as many scholars have argued, since many of the criteria in Dwyer \& Kim (2003) are applied to the national scale, some adjustments need to be made to fit a specific province like Nghe An as well as fit the form of sea and island tourism in Nghe An. Many criteria related to the sea and island will be added. At the same time, to simplify and avoid duplication, several criteria will be reduced or aggregated. The opinions of experts in the field of tourism are the basis for evaluating these criteria.

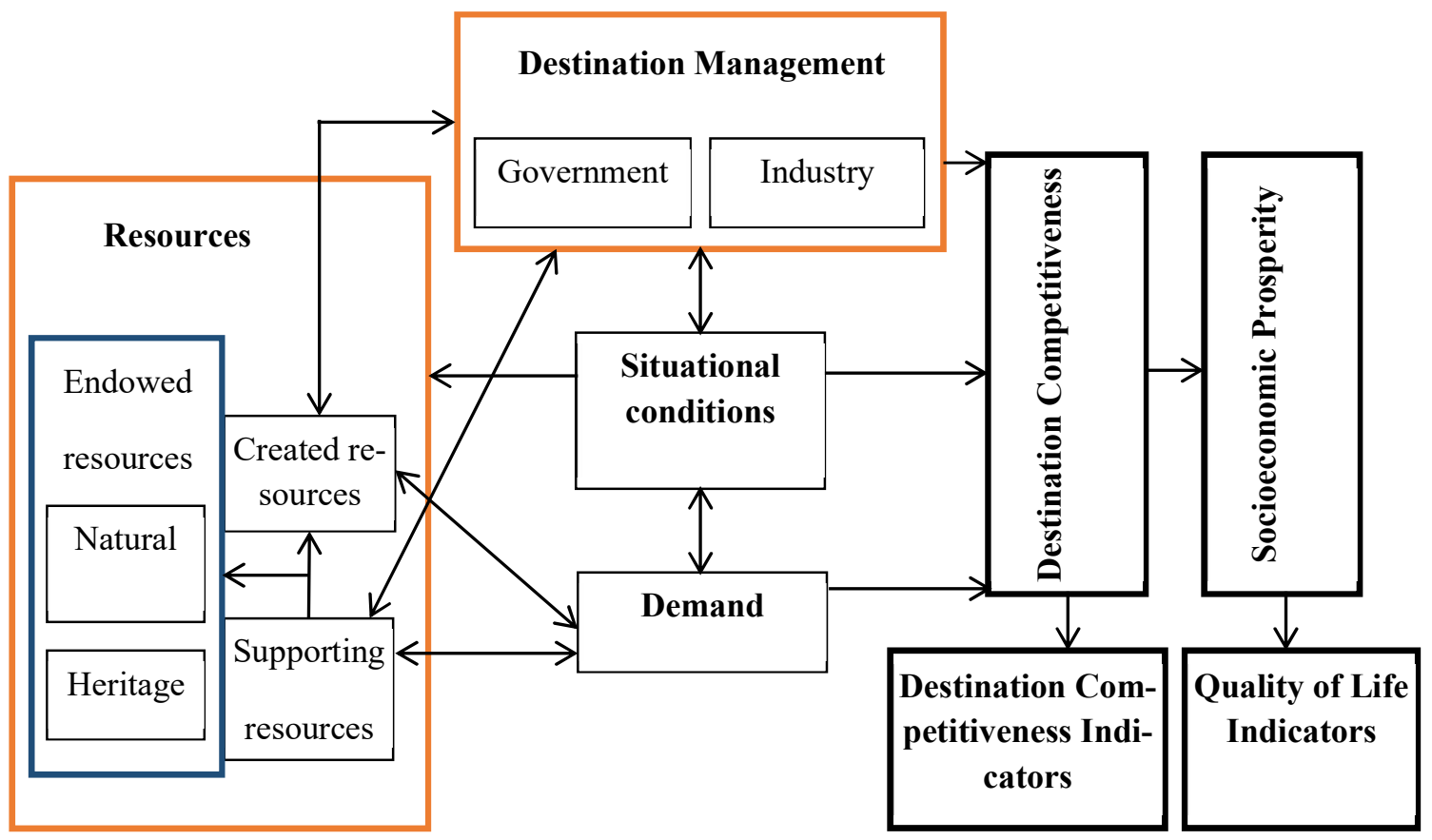

Fig. 1. Competitiveness assessment model for sea and island tourism in Nghe An

Thus, the competitiveness assessment model for sea and island tourism in Nghe An consists of five groups of factors connecting together based on the model of Dwyer and Kim (2003). Details of each group factors are as follows:

\section{(i) Resources}

The resources factor includes the following three types, as below:

The first, endowed resources: consists of two components of natural resources and cultural/ heritage resources. Sea and island tourism are tightly secured by endowed resources, so, many criteria related to beach, natural beauty of the sea and islands are added into the model. There are nine criteria in total to assess the endowed resources. The second, created resources contains five components including tourism infrastructure, play activities, shopping, entertainment and special events. There are 16 criteria in total to assess the created resources. The third, supporting resources: includes overall infrastructure, quality of service, transportation friendliness/ hospitality and market relations. There are 20 criteria to assess the supporting resources.

\section{(ii) Destination management}

This factor includes management activities of the government, such as: establishing an apparatus for tourism management; managing tourism promotion; making policy, planning and development; developing human resource and managing environment. Beside the management of the government, there are business management in the enterprises participating in the provision of tourism products and services. Regarding the duplication among the component criteria of each management activities in the original model of Dwyer and Kim (2003), the model used for Nghe An would reduce or merge similar criteria. There are 24 criteria in total to assess the destination management.

\section{(iii) Situational conditions}

This factor contains the following conditions: micro environment; location of destination; macro environment; price competition; safety/ security. Like the destination management factor, many duplicated criteria are reduced or merged. There are 26 
criteria in total to assess the situational conditions

\section{(iv) Demand}

In similarity to the original model in Dwyer and Kim (2003), there are only two criteria for assessing demand: tourists have known, heard or experienced destination; and tourists prefer to choose destination when travelling.

\section{(v) Tourism performance}

This section includes the following indicators: tourists' statistics; statistics on tourists' expenditure; the contribution of tourism to the local economy; investment in tourism; price competitiveness index; government support for tourism. Many duplicated criteria are reduced or merged. There are 21 criteria in total to assess the tourism performance. Although some performance indicators can be derived from direct analysis of data and facts, this part of the model is retained for three purposes. Firstly, the accuracy and reliability of experts' responses can be easily tested when compared with the reality. If the experts' responses are relevant to the reality, their responses in other sections are also reliable. Secondly, due to the inadequacy of data and practical situations of all provinces to compare with Nghe An, the experts' opinion on the questions in this section will contribute to the assessment of tourism performance in both five provinces. Thirdly, some performance indicators should be evaluated based on subjective assessment. In total, the five groups of factors have 118 criteria, less than in the Dwyer \& Kim model (2003).

\section{Research Methodology}

\subsection{Questionnaire design}

The questionnaire is designed based on the criteria system in the model in order to calculate the numerical value of the criteria in the practical model. In this study, each criterion was specified by a question (or perception) to get experts' opinions. The questionnaire includes questions about the personal information of the respondents and 118 comments, corresponding to 118 criteria in the designed model. Each criterion can be graded based on a given scale. Experimental studies based on the model of Dwyer and Kim (2003) normally use the Likert scale with 5 levels of evaluation. According to common practices, the Likert scale is also applied to the competitiveness assessment model for sea and island tourism in Nghe An. Accordingly, there are 5 levels (numbered from 1 to 5) for each criterion: 1 is Extremely Bad; 2 is Bad; 3 is Neutral; 4 is Good; and 5 is Extremely Good. At the same time, in order to make comparisons with relevant provinces, apart from Nghe An, some other sea and island destinations in Vietnam are selected for the survey. This is necessary because it not only compares the competitiveness of the sea and island tourism of Nghe An in relation to other destinations, but also creates a basis for assessing the accuracy of the survey results. In principle, selected provinces need to have characteristics in common with Nghe An, such as natural conditions, tourist resources, sea and island tourism products. In particular, besides Nghe An (NA), the following provinces are included in the questionnaire: Thanh Hoa (TH), Ha Tinh (HT), Da Nang (DN) and Khanh Hoa (KH). While Thanh Hoa (which is famous for Sam Son beach) and Ha Tinh (which is famous for Thien Cam beach) are two neighbouring provinces having many similarities with Nghe An, Da Nang (which is famous for Non Nuoc Beach) and Khanh Hoa (which is famous for the coastal city-Nha Trang) are two of the top destinations in the Central and the South. Comparisons between Nghe An and Thanh Hoa, Ha Tinh identify the differences that Nghe An needs to focus on to exploit in order to get more advantages while comparisons between Nghe An and Da Nang and Khanh Hoa help locate Nghe An on the national sea and island map.

\subsection{Sample}

150 experts' opinion sheets are issued and all received feedback. In general, experts give objective, honest answers to the questions from their own perspectives. Some of the main personal characteristics of the experts are consulted. The median age of the experts was 43, the group with the highest proportion being 41-50 (40\%) followed by the group of 31-40 (36\%) and the group of $51-60 \%(15.3 \%)$. This age structure reflects the goal of investigating those who are still working, having years of experience and a deep understanding of the practical situation. Most of the experts in the survey have undergraduate and postgraduate degrees. In terms of occupation, the experts are from different sectors such as state management, business, business, research-teaching and other occupations. Many of them are doing more than one job, especially both as a state manager and as a researcher or teacher. In these cases, a major occupation (usually the first occupation) will be selected. As a result, up to $60 \%$ do state management, nearly $30 \%$ do research, and $10 \%$ do business. Most of the respondents were living in the North with the major concentrate at central level, Ha Noi and Nghe An. To specify, 30\% are working for central offices, $28 \%$ in Nghe An and nearly $21 \%$ in Ha Noi. The respondents also came from all five investigated provinces. In order to test the reliability of the survey's results, the study analyzed differences of responses to each particular criterion based on their individual characteristics. For instance, the differences between male and female experts' responses or differences among the experts' responses from different provinces were examined. In particular, the following hypothesis tests will be conducted.

$$
\begin{aligned}
& \mathrm{H}_{0}: \mu_{\mathrm{ij}}\left|\mathrm{dd}_{\mathrm{k}}=\mu_{\mathrm{ij}}\right| \mathrm{dd}_{1} \\
& \mathrm{H}_{1}: \mu_{\mathrm{ij}}\left|\mathrm{dd}_{\mathrm{k}} \neq \mu_{\mathrm{ij}}\right| \mathrm{dd}_{1}
\end{aligned}
$$

where $\mu_{\mathrm{ij}}$ is the mean value of the criterion $i(i=1 \ldots 118$, corresponding to 118 questions in the questionnaire) of the province 
$j$ ( $j=$ Thanh Hoa, Nghe An, Ha Tinh, Da Nang, Khanh Hoa); dd is a personal characteristic of the interviewee (dd = gender, age, level, occupation, main residence/ workplace) and finally, $k$ and $l$ are different levels and groups of a characteristic (For example, male or female in gender characteristic). As a result, in most of cases, there is no basis for rejecting the $\mathrm{H}_{0}$ hypothesis at the significance level of $\alpha=5 \%$. It means that experts have relatively less comparable opinions in each criterion of each province, although they may differ from the others in individual characteristics. Moreover, the standard deviation of experts is relatively small in most of the cases. Therefore, we can come to the conclusion that the experts' opinions are quite focused and less influenced by their individual characteristics. Thus, the survey results can be trusted and used to compare and evaluate the competitiveness of the sea and island tourism in these provinces. In the analysis of the assessment results below, apart from 118 separate criteria corresponding to 118 questions, we also calculate and analyse aggregate criteria which include many separate criteria. Since the study does not evaluate the specific contribution of each particular criterion, the aggregate criteria are calculated by the simple average value of each criterion.

\section{Results and discussion}

\subsection{Current Competitive Competence}

\section{Resources for developing sea and island tourism}

Nghe An is generally evaluated above the average (3.2), higher than Thanh Hoa (2.9) and Ha Tinh (2.8) but lower than Da Nang (3.9) and Khanh Hoa (4.0). The indicators of its endowed resources and supporting resources are 3.4 while the indicator of its created resources is a bit lower at 2.8. The average standard deviation of the criteria is also relatively low (only about $15 \%-30 \%$ of the mean value), reflecting the concentration of the experts' responses.

Table 1

Assessment of resources for developing sea and island tourism

\begin{tabular}{|c|c|c|c|c|c|c|c|c|c|c|}
\hline & & & Iean & & & & & d Dev & & \\
\hline & TH & NA & HT & $\mathrm{DN}$ & $\mathrm{KH}$ & $\mathrm{TH}$ & NA & HT & DN & $\mathrm{KH}$ \\
\hline Average & 2.9 & 3.2 & 2.8 & 3.9 & 4.0 & 0.8 & 0.8 & 0.8 & 0.7 & 0.7 \\
\hline Endowed resources & 3.1 & 3.4 & 3.1 & 3.8 & 3.9 & 0.8 & 0.7 & 0.8 & 0.7 & 0.7 \\
\hline Created resources & 2.6 & 2.8 & 2.4 & 3.9 & 3.9 & 0.9 & 0.9 & 0.8 & 0.7 & 0.7 \\
\hline Supporting resources & 3.0 & 3.4 & 3.0 & 4.1 & 4.1 & 0.8 & 0.7 & 0.8 & 0.6 & 0.6 \\
\hline
\end{tabular}

In terms of endowed resources, natural resources of Nghe An are lower than cultural and heritage resources (3.2 and 3.5, respectively). In particular, in most of natural resource categories, Nghe An is slightly higher than Thanh Hoa and Ha Tinh, but much lower than Da Nang and Khanh Hoa. Experts consider the nature and beach of Nghe An with the biggest advantage while the climate and weather are the most unfavorable natural resource criteria. Meanwhile, the cultural and heritage criteria of Nghe An are equivalent to Da Nang and Khanh Hoa, and higher than Thanh Hoa and Ha Tinh. With Nghe An itself, cultural and heritage resources are also valued more than natural resources. In terms of cultural and heritage resources of Nghe An, monuments, museums, traditional arts and culture are highly appreciated, even the highest in all five provinces. Artistic and architectural features are the lowest cultural and heritage criteria of Nghe An. In terms of created resources, Nghe An is generally evaluated to be under the average (2.8), higher than Thanh Hoa (2.6) and Ha Tinh (2.4), but lower than Da Nang (3.9) and Khanh Hoa (3.9). In the created resources, entertainment of Nghe An has the lowest position (2.5) while the infrastructure rank the highest position (3.3). The supporting resources of Nghe An is at mid-level (3.4) among the investigated provinces, generally, higher than Thanh Hoa (3.0) and Ha Tinh (3.0), but lower than Da Nang (4.1) and Khanh Hoa (4.1). The friendliness and hospitality of Nghe An maintains the highest contributing factor (3.8) while the quality of service is rated the lowest (3.2).

\section{Local management of tourism}

In general, tourism management in Nghe An is also above the average (3.3), mid-level among the investigated provinces. The majority of the criteria is above average (3.0) and relatively close to each other. The two groups of criteria "tourism promotion management" and "human resource development" rank the highest score (3.4), but not much higher than the lowest score (3.2) of the criterion "policy making, planning and tourism development".

Table 2

Assessment of local government management of tourism

\begin{tabular}{|c|c|c|c|c|c|c|c|c|c|c|}
\hline & \multicolumn{5}{|c|}{ Mean } & \multicolumn{5}{|c|}{ Standard Deviation } \\
\hline & $\mathrm{TH}$ & NA & HT & $\mathrm{DN}$ & $\mathrm{KH}$ & $\mathrm{TH}$ & NA & HT & $\mathrm{DN}$ & $\mathrm{KH}$ \\
\hline Average & 2.9 & 3.3 & 2.9 & 4.0 & 3.9 & 0.9 & 0.8 & 0.9 & 0.7 & 0.7 \\
\hline State government management of tourism & 2.7 & 3.3 & 2.8 & 4.1 & 3.9 & 1.0 & 0.7 & 1.0 & 0.7 & 0.7 \\
\hline Management of local tourism promotion & 2.8 & 3.4 & 2.8 & 4.1 & 4.1 & 0.9 & 0.8 & 0.9 & 0.7 & 0.7 \\
\hline Policy making, planning and tourism development & 2.8 & 3.2 & 2.8 & 4.0 & 4.0 & 0.8 & 0.7 & 0.9 & 0.7 & 0.7 \\
\hline Human resource development & 3.1 & 3.4 & 3.0 & 3.8 & 3.8 & 0.9 & 0.7 & 0.9 & 0.7 & 0.7 \\
\hline Environmental management & 3.0 & 3.3 & 2.9 & 4.0 & 3.9 & 1.0 & 0.9 & 1.0 & 0.7 & 0.7 \\
\hline
\end{tabular}




\section{Situational conditions}

An expert assessment of situational conditions in Nghe An is shown in Table 3. The situational conditions in Nghe An are above the average (3.3), generally higher than Thanh Hoa (3.0) and Ha Tinh (3.0), but lower than Da Nang (3.9) and Khanh Hoa (3.8). All criteria of the situational conditions in Nghe An is above the average. The criterion "order protection/ safety/ security ranks the highest score while the "micro environment" gets the lowest score (3.2).

Table 3

Assessment of situational conditions

\begin{tabular}{|c|c|c|c|c|c|c|c|c|c|c|}
\hline & \multicolumn{5}{|c|}{ Mean } & \multicolumn{5}{|c|}{ Standard Deviation } \\
\hline & $\mathrm{TH}$ & NA & HT & $\mathrm{DN}$ & $\mathrm{KH}$ & $\mathrm{TH}$ & NA & HT & $\mathrm{DN}$ & $\mathrm{KH}$ \\
\hline Average & 3.0 & 3.3 & 3.0 & 3.9 & 3.8 & 0.8 & 0.7 & 0.8 & 0.7 & 0.7 \\
\hline Competitive environment (micro environment) & 2.9 & 3.2 & 2.8 & 3.9 & 3.9 & 0.8 & 0.7 & 0.8 & 0.6 & 0.7 \\
\hline Market position & 3.0 & 3.3 & 2.8 & 3.9 & 3.9 & 0.7 & 0.6 & 0.8 & 0.7 & 0.7 \\
\hline Macro environment & 3.1 & 3.3 & 3.1 & 4.0 & 4.0 & 0.8 & 0.7 & 0.8 & 0.6 & 0.6 \\
\hline Price competition & 3.0 & 3.3 & 3.0 & 3.7 & 3.7 & 0.7 & 0.7 & 0.7 & 0.7 & 0.7 \\
\hline Protection orders/ Safety/ Security & 3.1 & 3.6 & 3.3 & 4.2 & 3.8 & 1.1 & 0.7 & 0.9 & 0.7 & 0.6 \\
\hline
\end{tabular}

\section{Demand}

In terms of market demand, Nghe An is also rated at the middle level in comparison to other provinces. The market demand of Nghe An was scored at a moderate level (3.5). The two criteria of the market demand, reach the score in order of 3.6 and 3.5 .

Table 4

Assessment of demand

\begin{tabular}{|c|c|c|c|c|c|c|c|c|c|c|}
\hline & \multicolumn{5}{|c|}{ Mean } & \multicolumn{5}{|c|}{ Standard Deviation } \\
\hline & $\mathrm{TH}$ & NA & HT & $\mathrm{DN}$ & $\mathrm{KH}$ & $\mathrm{TH}$ & NA & HT & $\mathrm{DN}$ & $\mathrm{KH}$ \\
\hline Average & 2.9 & 3.5 & 2.7 & 4.4 & 4.5 & 1.0 & 0.7 & 0.9 & 0.7 & 0.7 \\
\hline Tourists have known, heard or experienced destination & 3.1 & 3.6 & 2.7 & 4.5 & 4.4 & 1.0 & 0.7 & 0.9 & 0.7 & 0.6 \\
\hline Tourists prefer to choose destination when travelling & 2.8 & 3.5 & 2.8 & 4.4 & 4.5 & 1.1 & 0.7 & 0.9 & 0.7 & 0.7 \\
\hline
\end{tabular}

\section{Tourism performance}

Similarly, tourism performance of Nghe An is generally slightly above the average (3.1), higher than Thanh Hoa (2.7) and Ha Tinh (2.6), but lower than Da Nang (4.0) and Khanh Hoa (4.1). The group indicators of tourists, expenditure, contribution, investment, price competition and support of the Nghe An government are scored relatively close together and better than Thanh Hoa and Ha Tinh but worse than Da Nang and Khanh Hoa. These results are well appropriate; hence, this is an important basis, proving that the experts' view is reliable.

Table 5

Evaluation of tourism performance

\begin{tabular}{|c|c|c|c|c|c|c|c|c|c|c|}
\hline & \multicolumn{5}{|c|}{ Mean } & \multicolumn{5}{|c|}{ Standard Deviation } \\
\hline & $\mathrm{TH}$ & NA & HT & $\mathrm{DN}$ & $\mathrm{KH}$ & $\mathrm{TH}$ & NA & HT & $\mathrm{DN}$ & $\mathrm{KH}$ \\
\hline Average & 2.7 & 3.1 & 2.6 & 4.0 & 4.1 & 0.8 & 0.7 & 0.8 & 0.7 & 0.7 \\
\hline Tourist & 2.7 & 3.2 & 2.6 & 4.2 & 4.4 & 0.8 & 0.7 & 0.8 & 0.6 & 0.6 \\
\hline Tourist's expenditure & 2.7 & 3.0 & 2.6 & 4.1 & 4.1 & 0.8 & 0.7 & 0.8 & 0.7 & 0.8 \\
\hline Contribution of tourism & 2.7 & 3.1 & 2.5 & 4.2 & 4.2 & 0.8 & 0.7 & 0.8 & 0.7 & 0.7 \\
\hline Investment in tourism & 2.7 & 3.0 & 2.6 & 4.0 & 4.0 & 0.7 & 0.7 & 0.7 & 0.7 & 0.7 \\
\hline Price competitiveness index & 2.7 & 3.1 & 2.7 & 3.8 & 4.1 & 0.7 & 0.5 & 0.7 & 0.6 & 0.8 \\
\hline Government support for tourism & 2.6 & 3.0 & 2.5 & 3.8 & 3.8 & 0.9 & 0.7 & 0.9 & 0.8 & 0.8 \\
\hline
\end{tabular}

\subsection{Reliability analysis}

\section{Evaluation of the scale by Cronbach's Alpha analysis}

Although Dwyer and Kim's (2003) competitiveness assessment model for sea and island tourism has been tested by various practical studies on its reliability, appropriateness as well as criteria of each group factor, its application into the circumstances in Vietnam still needs to be carefully assessed and examined. As usual, evaluating the scale using the Cronbach Alpha coefficient analysis is firstly implemented to eliminate the garbage or less important variables. As explained above, the applied model has a hierarchical structure. The entire model consists of 118 basic criteria, but these criteria are structured in different ways. Although there are five major groups of factors, each of the major groups has a different structure. For example, the group factor of demand is determined entirely by two criteria, while the remaining groups are formed by a number of subfactors. The sub-factors belong to the group of local management of tourism, the group of situational conditions, and the group of tourism performance and these sub-factors are determined by certain criteria. Meanwhile, the sub-factors belonging to the group of resources consist of many components, each of them is determined by specific criteria. Because of this reason, the structure of the model will remain the same when applying the Cronbach Alpha analysis. In other words, the Cronbach Alpha 
analysis will be applied to the basic criteria of each component (for example, components of the sub-factors in the group of tourism resources), sub-factors (for example, the sub-factors in the group of local management of tourism, situational conditions, tourism performance), or the group factors of demand. Except for components or sub-factors that have only one criterion, the total number of Cronbach's Alpha analysis to be conducted is 27. The Cronbach's Alpha analysis was applied to each surveyed province. Due to the large number of attributes, this section only summarizes the main results. The synthesis of the Cronbach's Alpha analysis was conducted based on common rules to determine if the criteria are appropriate with Cronbach's Alpha> 0.6 (Nunnally \& Burnstein, 1994). Only results that do not meet all these rules are analyzed in this section.

Table 6

Results of the Cronbach's Alpha analysis

\begin{tabular}{|c|c|c|c|}
\hline Province & Component/ Sub-factor/ Group factor & $\begin{array}{c}\text { Cronbach's } \\
\text { Alpha }\end{array}$ & Suggestion \\
\hline Thanh Hoa (TH) & Market position & 0.548 & Eliminate the criterion "Difference compared to other localities" \\
\hline \multirow{7}{*}{ Nghe An (NA) } & Friendly/ Hospitality & 0.482 & Combine two criteria "friendliness" and "support" \\
\hline & Market relations & 0.287 & Eliminate the criterion "Other Relations \\
\hline & Local management of tourism promotion & 0.485 & Combine some criteria \\
\hline & Macro environment & 0.396 & Combine some criteria \\
\hline & Price competition & 0.535 & Combine some criteria \\
\hline & Domestic tourists & 0.389 & Combine some criteria \\
\hline & Price competitiveness index & 0.507 & Combine two criteria "Expenditure" and "Expenditure ratio" \\
\hline \multirow{3}{*}{ Ha Tinh (HT) } & Endowed resources & 0.535 & Combine some criteria \\
\hline & Friendly/ Hospitality & 0.574 & Combine two criteria "friendliness" and "support" \\
\hline & Market relations & 0.580 & Combine some criteria \\
\hline \multirow{5}{*}{ Da Nang (DN) } & Endowed resources & 0.574 & Combine some criteria \\
\hline & Transportation & 0.354 & Combine some criteria or eliminate the criterion "Visiting other places" \\
\hline & Friendly/ Hospitality & 0.553 & Combine two criteria "friendliness" and "support" \\
\hline & Market relations & 0.464 & Combine some criteria \\
\hline & Investment in tourism & 0.485 & Combine some criteria \\
\hline \multirow{5}{*}{ Khanh Hoa (KH) } & Endowed resources & 0.559 & Combine some criteria \\
\hline & Transportation & 0.538 & Combine some criteria or eliminate the criterion "Visiting other places" \\
\hline & Market relations & 0.535 & Combine some criteria \\
\hline & Macro environment & 0.396 & Combine some criteria \\
\hline & Investment in tourism & 0.525 & Combine some criteria \\
\hline
\end{tabular}

The results show that the model is generally reliable as there is a little number of components/ group factors having a low Cronbach Alpha coefficient. Most of analyses have the Cronbach Alpha coefficient higher than 0.6. In order to make a better model, some components and group factors should be re-adjusted. However, provinces differ from the others in components and group of factors which need to be adjusted, so it is still acceptable to retain the criteria as originally designed.

\section{Conclusion and discussion}

The exploratory factor analysis (EFA) helps to retain groups of criteria after analyzing the Cronbach Alpha coefficient on a number of key components. Basically, EFA simplifies the whole process. As can be seen from the Cronbach Alpha analysis, all the criteria of the model could be retained without affecting on the quality of the analysis. However, due to the complex structure and hierarchy, the EFA cannot be implemented for all criteria as normal criteria but applied to certain criteria. In particular, the EFA analysis will be conducted for criteria of local management of tourism, situational conditions, and demand and tourism performance. With the group factors of resources, the EFA analysis will be applied to sub-factors such as endowed resources, created resources and supporting resources. The EFA analysis was applied to all provinces with collected data using SPSS software. The principal components analysis (PCA) method and the rotated method Varimax are conducted. In general, since the KMO coefficient is quite high (higher than 0.5), the significance is low (equal to 0.000) and the total variance explained is higher than $50 \%$, the results of exploratory factor analysis (EFA) are reliable (Hair et al., 2006). The initial design of the model is consistent with the EFA results in the number of extracts belong to "supporting resources", "local management of tourism, and "demand". With the sub-factor "endowed resources", the number of components should be increased to 3 instead of 2 as in the initial design. Thus, the "culture/ heritage" component can be split into two different components. With the sub-factor "created resources", the number of components should be reduced to 3 instead of 5 as in the initial design. Thus, the "shopping", "entertainment" and "event/ ceremony" factors could be combined into one. With the factor "situational conditions", the sub-factors should be increased to 7 instead of 5 as in the initial design. So, both of the sub-factors "micro environment" and "macro environment" could be split in two. With the factor "tourism performance", the number of subfactors should be reduced to 5 instead of 6 as in the initial design. The sub-factors "tourists" and "tourists" expenditure" could be combined into one. In general, the competitiveness assessment model for sea and island tourism is reliable enough to analyze the surveyed results. In short, the competitiveness of the sea and island tourism in Nghe An is in the middle of the five provinces studied, reached between Neutral and Good. The competitiveness of Nghe An is higher than Thanh Hoa and Ha Tinh but much lower than Da Nang and Khanh Hoa. The market demand is considered as the strongest aspect of sea and island tourism in Nghe An while the tourism performance is the lowest criterion among five localities. Those results show that there was a gap between the competitiveness of the sea and island tourism in Nghe An compared to the top localities of Vietnam. However, in terms of the neighboring provinces, Nghe An has relatively advanced capacities. This dominance results from efforts to increase the added value of endowed tourism resources, for example, through the development of created resources and supporting resources, the quality improvement of tourism management, and the improvement of situational conditions. 
Table 7

Results of exploratory factor analysis

\begin{tabular}{|c|c|c|c|c|c|}
\hline Province & $\begin{array}{l}\text { Group factor } / \\
\text { Sub-factor }\end{array}$ & $\begin{array}{l}\text { No. of compo- } \\
\text { nent/sub-factors }\end{array}$ & KMO & $\begin{array}{c}\text { Number of } \\
\text { extracted components }\end{array}$ & $\begin{array}{l}\text { Total Variance } \\
\text { Explained (\%) }\end{array}$ \\
\hline \multirow{7}{*}{ Thanh Hoa (TH) } & Endowed resources & 2 & 0.756 & 2 & 59.15 \\
\hline & Created resources & 5 & 0.906 & 2 & 67.58 \\
\hline & Supporting resources & 5 & 0.810 & 4 & 69.73 \\
\hline & Local tourism management & 5 & 0.912 & 4 & 80.59 \\
\hline & Situational performance & 5 & 0.841 & 7 & 79.51 \\
\hline & Demand & 1 & 0.500 & 1 & 82.67 \\
\hline & Tourism performance & 6 & 0.836 & 4 & 73.32 \\
\hline \multirow{7}{*}{$\begin{array}{l}\text { Nghe An } \\
\text { (NA) }\end{array}$} & Endowed resources & 2 & 0.568 & 3 & 78.85 \\
\hline & Created resources & 5 & 0.845 & 3 & 92.00 \\
\hline & Supporting resources & 5 & 0.750 & 5 & 66.29 \\
\hline & Local tourism management & 5 & 0.830 & 6 & 74.49 \\
\hline & Situational performance & 5 & 0.765 & 7 & 75.37 \\
\hline & Demand & 1 & 0.500 & 1 & 74.57 \\
\hline & Tourism performance & 6 & 0.792 & 5 & 75.31 \\
\hline \multirow{7}{*}{$\begin{array}{l}\text { Ha Tinh } \\
(\mathrm{HT})\end{array}$} & Endowed resources & 2 & 0.613 & 3 & 65.03 \\
\hline & Created resources & 5 & 0.895 & 3 & 70.79 \\
\hline & Supporting resources & 5 & 0.822 & 5 & 72.88 \\
\hline & Local tourism management & 5 & 0.904 & 4 & 79.21 \\
\hline & Situational performance & 5 & 0.827 & 7 & 76.35 \\
\hline & Demand & 1 & 0.646 & 1 & 82.28 \\
\hline & Tourism performance & 6 & 0.840 & 5 & 77.68 \\
\hline \multirow{7}{*}{$\begin{array}{l}\text { Da Nang } \\
(\mathrm{DN})\end{array}$} & Endowed resources & 2 & 0.638 & 3 & 63.42 \\
\hline & Created resources & 5 & 0.837 & 4 & 71.02 \\
\hline & Supporting resources & 5 & 0.639 & 7 & 76.52 \\
\hline & Local tourism management & 5 & 0.835 & 5 & 67.11 \\
\hline & Situational performance & 5 & 0.727 & 8 & 76.45 \\
\hline & Demand & 1 & 0.699 & 1 & 84.95 \\
\hline & Tourism performance & 6 & 0.771 & 5 & 73.60 \\
\hline \multirow{7}{*}{ Khanh Hoa (KH) } & Endowed resources & 2 & 0.752 & 3 & 69.73 \\
\hline & Created resources & 5 & 0.805 & 4 & 71.04 \\
\hline & Supporting resources & 5 & 0.741 & 5 & 69.88 \\
\hline & Local tourism management & 5 & 0.825 & 6 & 72.21 \\
\hline & Situational performance & 5 & 0.727 & 7 & 72.48 \\
\hline & Demand & 1 & 0.500 & 1 & 77.13 \\
\hline & Tourism performance & 6 & 0.770 & 5 & 72.82 \\
\hline
\end{tabular}

\section{References}

Cracolici, M. F., Nijkamp, P. \& Rietveld, P. (2008). Assessment of tourism competitiveness by analysing destination efficiency. Tourism Economics, 14(2), 325-342.

Crouch, G. I. (2010). Destination competitiveness: An analysis of determinant attributes. Journal of Travel Research, 50(1), 27-45.

Crouch, G. I. \& Ritchie, J. R. B. (1999). Tourism, competitiveness, and social prosperity. Journal of Business Research, 44, $137-52$.

Dong, X. D. (2017). Factor affecting tourist destination choice: A survey of international travelers to Hanoi, Vietnam. Journal of Economics and Development, 19(1), 77-92.

Duman, T. \& Kozak M. (2010). The Turkish tourism product: Differentiation and competitiveness. Anatolia: An International Journal of Tourism and Hospitality Research, 21(1), 89-106.

Dwyer, L. \& Kim, C. (2003). Destination competitiveness: Determinants and indicators. Current Issues in Tourism, 6(5), $369-414$.

Enright, M. J. \& Newton, J. (2005). Determinants of tourism destination competitiveness in Asia Pacific: Comprehensiveness and universality. Journal of Travel Research, 43, 339-350.

Gomezelj, D. O. \& Mihalič, T. (2008). Destination competitiveness - Applying different models, the case of Slovenia. Tourism Management, 29, 294-307.

Hair, J. F., Black, W. C., Babin, B. J., Anderson, R. E. \& Tatham, R. L. (2006). Multivariate data analysis (6 $6^{\text {th }}$ ed.), Pearson Prentice Hall.

Hassan, S. S. (2000). Determinants of market competitiveness in an environmentally sustainable tourism industry. Journal of Travel Research, 38, 239-245.

Hudson, S., Ritchie, B. \& Timur, S. (2004). Measuring destination competitiveness: An empirical study of Canadian Ski resorts. Tourism and Hospitality Planning \& Development, 1(1), 79-94.

Nunnally, J. \& Berstein, I.H. (1994). Pschychometric Theory. (3 ${ }^{\text {rd }}$ ed.), New York: McGraw-Hill.

Porter, M.E. (1990). The Competitive Advantage of Nations. The Free Press, New York.

Ritchie, J. R B. \& Crouch, G. I. (1993). Competitiveness in international tourism: A framework for understanding and analysis. Proceedings of the 43rd Congress of the Association Internationale d'Experts Scientifique due Tourisme on Competitiveness of Long-Haul Tourist Destinations, St. Gallen, Switezerland: A.I.E.S.T., 23-71.

Ritchie, J. R. B. \& Crouch, G. I. (2000). The competitive destination, a sustainable perspective. Tourism Management, 21(1), 1-7.

Ritchie, J. R. B. \& Crouch, G. I. (2003). The Competitive Destination: A Sustainable Tourism Perspective. Wallingford, UK: CABI Publishing.

Tanja, A., Vladimir M., Nemanja, D. \&Tamara, J. (2011). Integrated model of destination competitiveness. Geographica Pannonica, 15(2), 58-69.

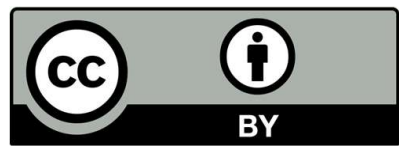

(C) 2020 by the authors; licensee Growing Science, Canada. This is an open access article distributed under the terms and conditions of the Creative Commons Attribution (CC-BY) license (http://creativecommons.org/licenses/by/4.0/). 